\title{
DOE/ER/13339--T)
}

\section{MOLECULAR CHARACTERIZATION OF BACTERIAL RESPIRATION ON MINERALS}

FINAL TECHNICAL REPORT

August, 1996

$85 \quad 13339$

\author{
RECEIVED \\ MAY 111998 \\ OSTI
}

Grant No. DE-FG05-94ER20157

DISTRIBUTION OF THIS DOCUMENT IS UNLIMITED
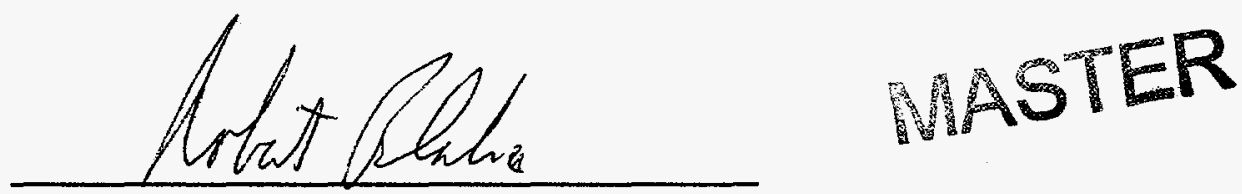

Robert Blake II, Principal Investigator

College of Pharmacy

Xavier University

New Orleans, Louisiana

70125

APPROVED FOR RELEASE OR

PUBLICATION. INTEL. PROP. GP., OFC. OF CHIEF COUNSEL, DOE1OFO F. EQulon 518198 


\section{DISCLAIMER}

This report was prepared as an account of work sponsored by an agency of the United States Government. Neither the United States Government nor any agency thereof, nor any of their employees, makes any warranty, express or implied, or assumes any legal liability or responsibility for the accuracy, completeness, or usefulness of any information, apparatus, product, or process disclosed, or represents that its use would not infringe privately owned rights. Reference berein to any specific commercial product, process, or service by trade name, trademark, manufacturer, or otherwise does not necessarily constitute or imply its endorsement, recommendation, or favoring by the United States Government or any agency thereof. The views and opinions of authors expressed herein do not necessarily state or reflect those of the United States Government or any agency thereof. 


\section{DISCLAIMER}

Portions of this document may be illegible electronic image products. Images are produced from the best available original document. 


\section{SUMMARY}

The scope of work outlined in the original proposal contained two specific aims. Highlights of the results obtained and published on each specific aim during the grant period in question are summarized below:

Specific Aim \#1 - To continue the identification, separation, and characterization of the cellular components necessary for aerobic respiration on iron.

An electrochemical apparatus for the large scale cultivation of chemolithotrophic bacteria that respire aerobically on ferrous ions was perfected and described in a peer-reviewed puólication (reprint attached).

- The kinetic properties of an acid-stable iron:rusticyanin oxidoreductase from $T$. ferrooxidans were determined and described in a peer-reviewed publication (reprint attached).

- The overall tertiary structure of rusticyanin in solution was elucidated from a combination of homonuclear proton and heteronuclear ${ }^{15} \mathrm{~N}$-edited NMR spectra. The resonance assignments were reported in a peer-reviewed publication (reprint attached).

An artificial gene for rusticyanin was designed, synthesized, and successfully expressed in E. coli. Cassette-replacement mutagenesis established that His85 was the fourth ligand to the blue copper center of the protein. These results were described in a peer-reviewed publication (reprint attached).

- The X-ray crystallographic structure of rusticyanin was solved to a resolution of 1.9 $\AA$ by multiwavelength anomalous dispersion (MAD) phasing. The complete crystallographic structure of the oxidized protein was described in a peer-reviewed publication (reprint attached).

Specific Aim \#2 - To initiate an investigation of the molecular principles whereby these bacteria recognize and adhere to their insoluble inorganic substrates.

- The electrophoretic mobility of $T$. ferrooxidans with and without its insoluble substrates was determined by laser Doppler velocimetry under physiological conditions. These measurements indicated that electrostatic interactions did not provide part of the driving force for adherence, rather the net surface charge on the bacterium was such as to minimize charge repulsive forces in its interations with sharged mineral surfaces. These results were described in a peer-reviewed publication (reprint attached).

The adherence of $T$. ferrooxidans to the surface of pyrite was observed directly in a video-enhanced light microscope. Principal features of the observed adherence phenomenon were described in a manuscript published in conjunction with the biennial international biohydrometallurgy meeting held in 1995 in Santiago, Chile (reprint attached). 


\section{SUMMARY OF UNPUBLISHED DATA OR DATA NOT PRESENTED IN ATTACHED REPRINTS}

Novel redox-active biomolecules were demonstated in different iron autotrophs

As part of a continuing effort to identify and investigate the biomolecules responsible for aerobic respiration on soluble ferrous ions, this laboratory conducted a comparative study of the principal electron transport components expressed during autotrophic growth by representative members of each of the 5 phylogenetically distinct groups of iron-oxidizing organisms that are currently recognized. These investigations revealed that phylogenetically distinct groups of ironoxidizing organisms, in turn, express biochemically distinct electron transport chains when grown chemolithotrophically on iron. Each type of electron transport chain was characterized by its own distinctive acid-stable, redox-active biomolecule. Absorbance spectra of the principal acid-stable biomolecules expressed by each group are presented in Fig. 1. Each spectrum in Fig. 1 represents a highly purified protein that is stable and redox-active in $0.01 \mathrm{~N}$ sulfuric acid. Fig. 1A shows the oxidized and reduced spectra of rusticyanin, the type I blue copper protein that dominates the electron transport chains of Thiobacillus ferrooxidans and strain $m-1$. Fig. $1 \mathrm{~B}$ shows the oxidized and reduced spectra of the novel red cytochrome (cytochrome 579) that dominates the electron transport chains of Leptospirillum ferrooxidans and similar organisms. The alkaline pyridine hemochromogen spectrum of this cytochrome revealed that it was clearly not an $a$-, $b$-, or $c$-type heme (data not shown), and that it represents a new, heretofore undescribed, heme with a novel structure unique to respiratory iron oxidation in these organisms. Fig. 2C shows the oxidized and reduced spectra of the novel yellow chromophore (factor 458) that dominates the electron transport chains of Sulfobacillus thermosulfidooxidans and other Gram-positive moderate thermophiles that respire on iron. Fig. 2D shows the oxidized and reduced spectra of the novel yellow cytochrome (cytochrome 572) that dominates the electron transport chains of Metallosphaera sedula and other extremely thermophilic archaebacteria.

\section{Structural and functional studies were initiated on purified cytochrome 579.}

Cytochrome 579 was purified to electrophoretic homogeneity from cell-free extracts of Leptospirillum ferrooxidans. L. ferrooxidans appeared to express no rusticyanin whatsoever; instead, it produced abundant quantities of this acid-stable red cytochrome when grown on ferrous ions. Sodium dodecyl sulfate polyacrylamide gel electrophoresis under reducing conditions revealed that the purified protein was comprised of a single polypeptide with an apparent molecular weight of around 16,000 daltons. A more precise determination of the subunit molecular weight was obtained by liquid chromatography coupled with electrospray mass spectrometry in collaboration with Dr. Jack Shively at the City of Hope, Duarte, CA. The inset of Fig. 2 shows the positive-ion electrospray mass spectrum of cytochrome 579. The main figure shows the deconvoluted spectrum for the neutral cytochrome obtained using operating and analysis software provided with the mass spectrometer. Two major peaks were obtained at 16,140 and 16,015 daltons. The small mass differences could derive from missing $\mathrm{N}$ - or $\mathrm{C}$ terminal amino acids due to proteoly sic astivity during preparation cr from post-translational modification of part of the sample. 
The molecular weight of cytochrome 579 in solution was determined by Rayleigh light scattering analysis on a Dawn DSP laser photometer equipped with multiple detectors. Fig. 3 shows a Debye plot obtained with 5 concentrations of the native cytochrome. Extrapolation of the data to zero angle and zero concentration yielded a molecular weight of the native protein of around 115,000 daltons, a value very close to that anticipated for an oligomer composed of eight subunits.

Efforts to determine the primary sequence of this protein are in progress in collaboration with Dr. Jack Shively at the City of Hope in Duarte, CA. The primary sequence of about half of the protein has been completed and verified. Collaborative experiments with Dr.Russ Timkovich, University of Alabama, have revealed that the heme prosthetic group (a derivative of heme $\boldsymbol{A}$ ) is covalently linked to the polypeptide by a sulfhydryl bond (a novel construction found elsewhere only in myeloperoxidase).

The apparent reduction potential of the purified protein was determined to be around 670 $\mathrm{mV}$. The purified red cytochrome was redox-active with ferrous ions at acid $\mathrm{pH}$. The dependence of the pseudo-first order rate constant for the Fe(II)-dependent reduction of the cytochrome was decidedly nonlinear; the reaction order with respect to the concentration of ferrous ions was between 3 and 4 . Further efforts to characterize the kinetic properties of that electron-transfer reaction by stopped flow spectrophotometry are in progress. It is anticipated that these studies will culminate in the preparation of a manuscript to a peer-reviewed journal by the end of this year.

Highly purified preparations of factor 458 from $S$. thermosulfidooxidans and cytochrome 572 from $M$. sedula were also developed during the current grant period. SDS-PAGE on purified factor 458 revealed two bands of equal staining intensity at apparent molecular weights of 8,000 and 12,000 daltons. It is anticipated that structural and functional studies on these two respiratory components will commence once our investigations of cytochrome 579 have entered the manuscript preparation stage. 


\section{FIGURE LEGENDS}

Fig. 1. Absorbance spectra of oxidized (solid line) and reduced (dashed line) acid-stable proteins from acidophilic iron-0xidizing bacteria. All spectra were determined on purified proteins in $0.01 \mathrm{~N}$ sulfuric acid at $25^{\circ} \mathrm{C}$. The absorbance spectrum of each reduced protein was determined $10 \mathrm{~min}$ after mixing the sample of oxidized protein with an excess of ferrous sulfate. $A$, rusticyanin from $T$. ferrooxidans. $B$, cytochrome 579 from $L$. ferrooxidans. Inset, a difference spectrum representing the absolute spectrum of the Fe(II)-reduced protein minus that of the oxidized protein. $C$, factor 458 from $S$. thermosulfidooxidans. Inset, a difference spectrum representing the absolute spectrum of the oxidized protein minus that of the $\mathrm{Fe}$ (II)-reduced protein. $D$, cytochrome 572 from $M$. sedula. Inset, a difference spectrum representing the absolute spectrum of the $\mathrm{Fe}$ (II)-reduced protein minus that of the oxidized protein.

Fig. 2. Deconvoluted positive-ion electrospray mass spectrum of cytochrome 579, showing the mass of the neutral protein. Inset, primary mass spectral data upon which the deconvolution was based.

Fig. 3. Debye light scattering plot for native cytochrome 579. Concentration of cytochrome $579 \mathrm{in} \mathrm{g/ml:} \mathrm{closed} \mathrm{circles,} \mathrm{1.15;} \mathrm{open} \mathrm{circles,} \mathrm{2.31;} \mathrm{closed} \mathrm{triangles,} \mathrm{3.46;} \mathrm{open} \mathrm{triangles,} \mathrm{4.62;}$ and closed squares, 5.77. Measurements were performed in $0.01 \mathrm{~N}$ sulfuric acid. $R(\theta)$ is the Rayleigh ratio, $\theta$ is the angle between the incident and the scattered light, $\mathrm{K}$ is an instrument constant, $\mathrm{c}$ is the concentration of cytochrome 579, and 8934 is an arbitrary constant that permits an appropriate spread of the data for plotting. The dashed lines represent extrapolation to zero angle (horizontal line) and zero concentration (vertical line). 


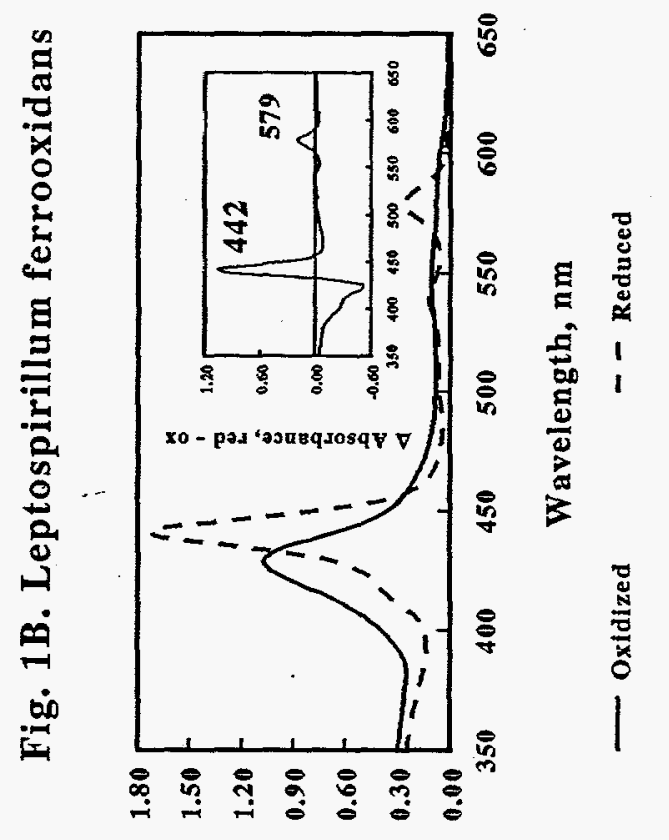

วouequosq

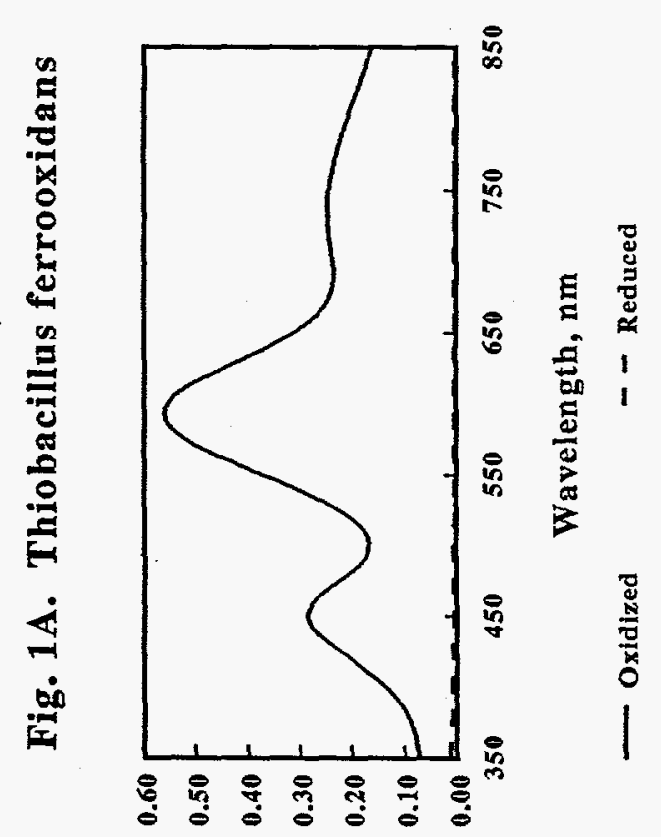

วouequosqv

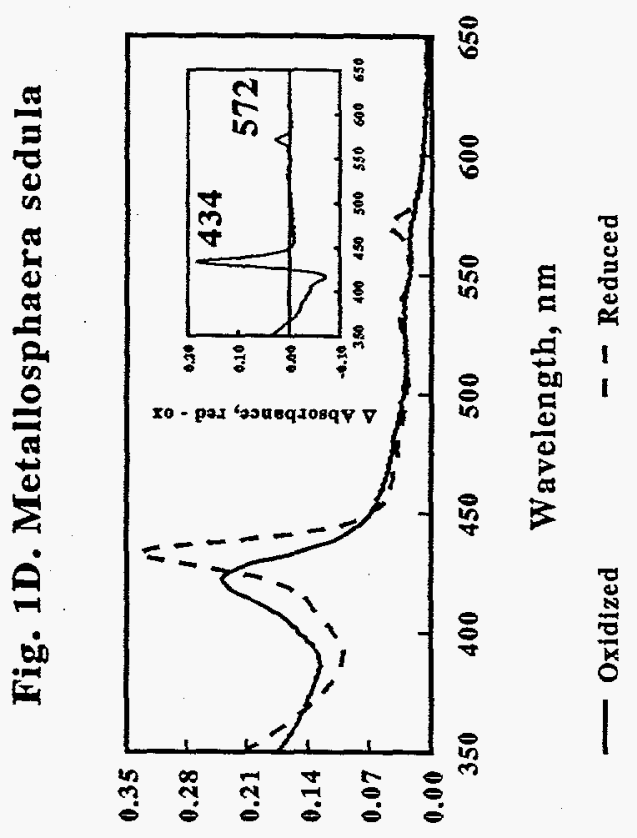

ววurq.xosqY

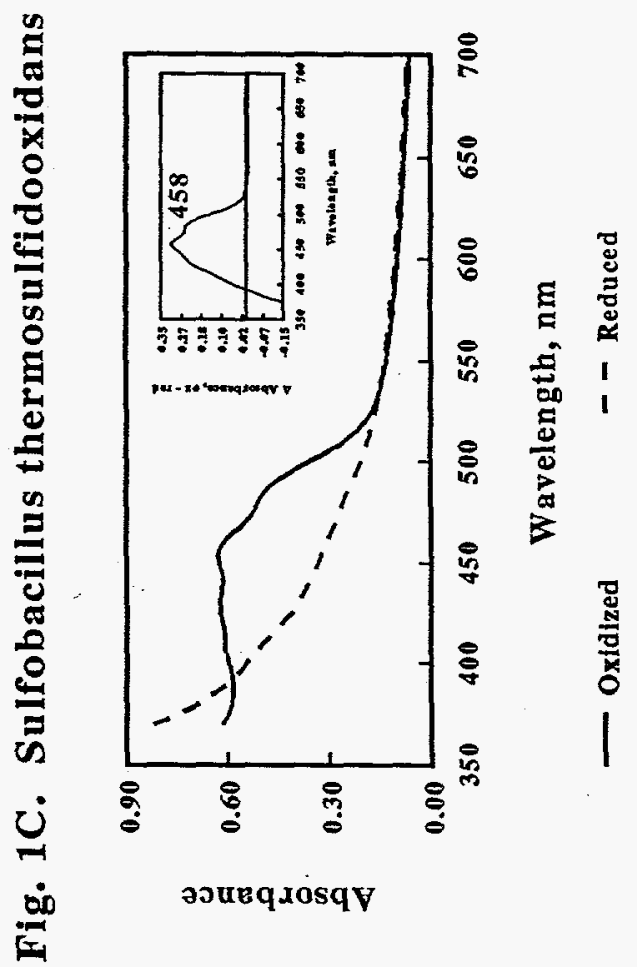


Fig. 2. Electrospray mass spectrum of cytochrome 579

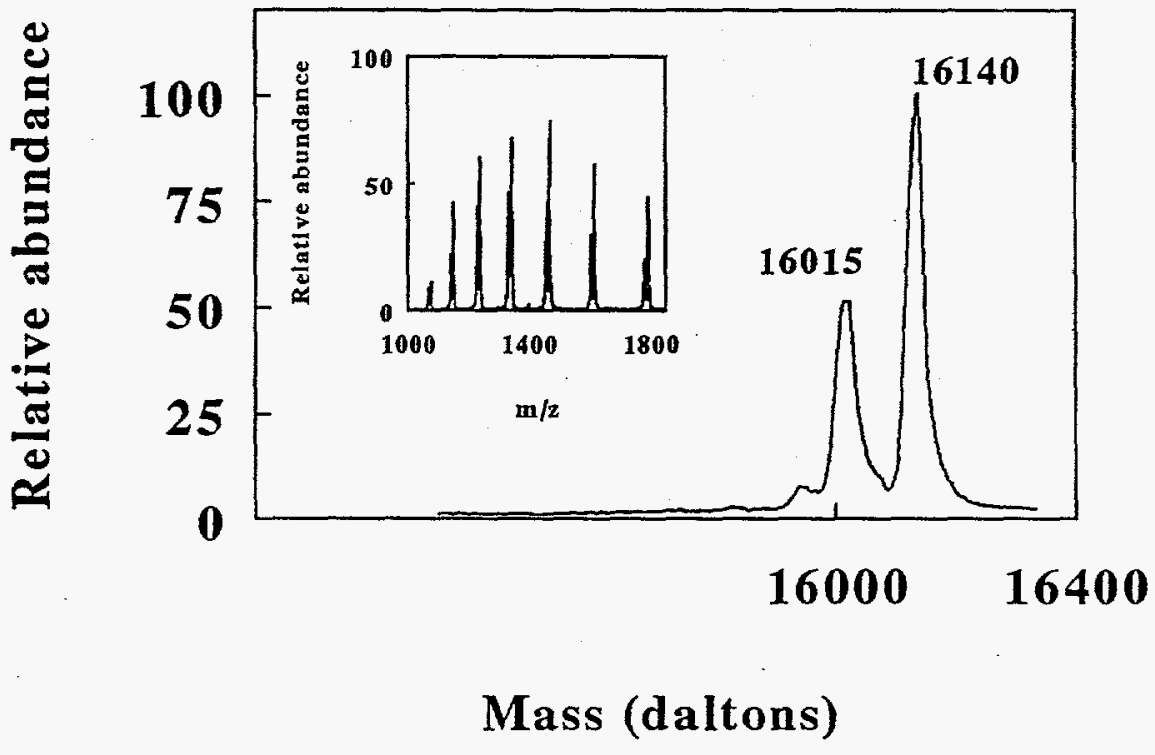

Fig. 3. Debye plot of cytochrome 579

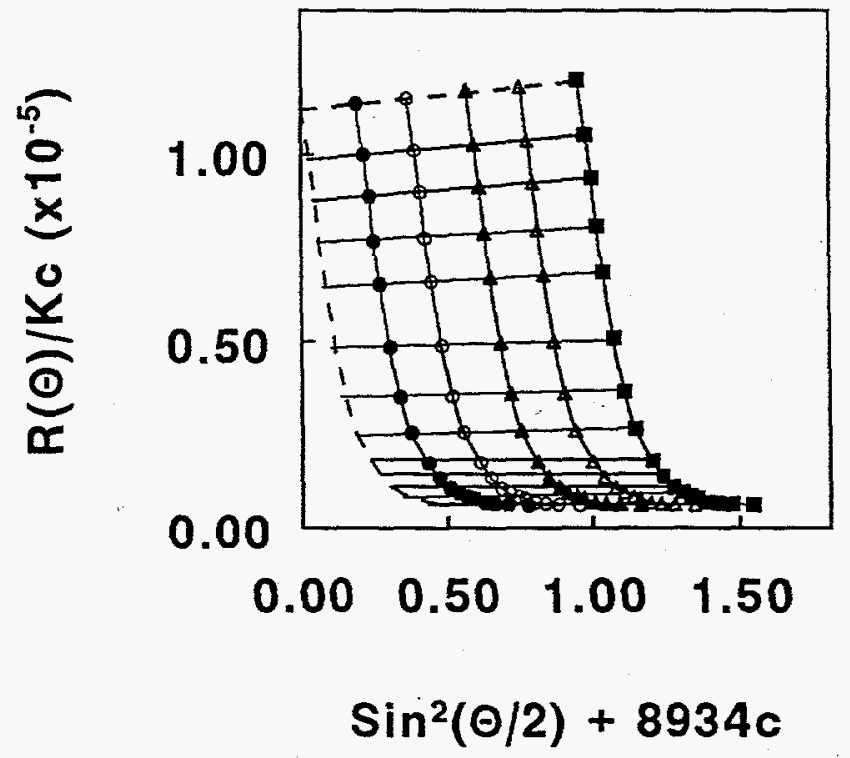

